\title{
Acute Oral Toxicity and Genotoxicity of Polysaccharide Fraction from Young Barley Leaves (Hordeum vulgare L.)
}

\author{
Chang-Won Cho ${ }^{1}\left(\mathbb{D}\right.$, , Young-Ran Song ${ }^{1,+}{ }^{1}$, Won-Chul Lim ${ }^{1}$, Youn-Hwan Hwang ${ }^{2,3}{ }^{\circledR}$, \\ Young Kyoung Rhee ${ }^{1}$, Jae Woong Choi ${ }^{1}$, Kyung-Tae Lee ${ }^{4}(\mathbb{D})$ and Hee-Do Hong ${ }^{1, *}$ \\ 1 Research Group of Traditional Food, Korea Food Research Institute, Wanju-gun, Jeollabuk-do 55365, Korea; \\ cwcho@kfri.re.kr (C.-W.C.); songyr28@efact.or.kr (Y.-R.S.); 07934@kfri.re.kr (W.-C.L.); \\ ykrhee@kfri.re.kr (Y.K.R.); choijw@kfri.re.kr (J.W.C.) \\ 2 Herbal Medicine Research Division, Korea Institute of Oriental Medicine, Daejeon 34054, Korea; \\ hyhhwang@kiom.re.kr \\ 3 Korean Convergence Medicine Major KIOM, University of Science \& Technology (UST), \\ Daejeon 34054, Korea \\ 4 Department of Pharmaceutical Biochemistry, College of Pharmacy, Kyung Hee University, Seoul 02447, \\ Korea; ktlee@khu.ac.kr \\ * Correspondence: honghd@kfri.re.kr; Tel.: +82-63-219-9285 \\ + Current affiliation: Technology Evaluation Team, Foundation of Agricultural Technology Commercialization \\ and Transfer, Iksan 54667, Korea.
}

Received: 20 May 2020; Accepted: 16 June 2020; Published: 19 June 2020

check for updates

\begin{abstract}
Polysaccharides isolated from various plants are considered precious bioactive materials owing to their potent biological activities. Previously, we prepared a polysaccharide fraction (BLE0) isolated from young barley leaves (Hordeum vulgare L.), demonstrating its anti-osteoporotic and immunostimulatory activities. However, data regarding BLE0 toxicity is lacking. To establish its safety, in vitro genotoxicity (chromosomal aberration and bacterial reverse mutation assays) and acute oral toxicity assays were conducted. In the in vitro genotoxicity assays, bacterial reverse mutation and chromosomal aberration assays showed that BLE0 possessed no mutagenicity or clastogenicity. Furthermore, the median lethal dose $\left(\mathrm{LD}_{50}\right)$ of $\mathrm{BLE} 0$ was higher than $5000 \mathrm{mg} / \mathrm{kg}$ in female and male Sprague-Dawley (SD) rats and no adverse effects were observed in terms of mortality and abnormal changes in clinical signs (body weight and necropsy). Based on these results, BLE0 was found to be safe with regards to genotoxicity under our test conditions, demonstrating no acute oral toxicity up to $5000 \mathrm{mg} / \mathrm{kg}$ in SD rats.
\end{abstract}

Keywords: Hordeum vulgare L.; polysaccharides; toxicity

\section{Introduction}

Barley (Hordeum vulgare L.) is an edible crop belonging to the family Poaceae, and is mainly used as a food source in East Asia, including Korea [1]. Barley is known to contain various functional ingredients such as lutonarin, saponarin, $\beta$-glucan and various policosanols [2,3]. Particularly, it has been reported that after seeding, young barley leaves (15-20 $\mathrm{cm}$ in size) contain a large amount of superoxide dismutase and vitamin $C$, which decompose free radicals [4]. Additionally, young barley leaves contain a large amount of saponarin, which demonstrates improved liver function as well as inhibits $\alpha$-glucosidase, a diabetes-related enzyme, among polyphenol compounds $[5,6]$. Studies evaluating the various biological activities of the young barley leaf, such as antioxidant, antidiabetic, antidepressant and hypolipidemic effects, have been reported [1,2,7-9]. 
To date, most physiological studies using the young barley leaf have been conducted with solvent extracts containing small molecules, such as saponarin, as the main active ingredient. In addition to plant-derived bioactive small molecules, various biological properties (immune-enhancing, anti-inflammatory, antiviral, and anticancer activities) of plant-derived polysaccharides, major high-molecular-weight plant substances, have been recently reported [10,11]. According to recent research trends, we purified the pectinase-treated polysaccharide fraction (BLE0) from young barley leaves. Furthermore, we reported immune-enhancing and antiosteoporotic activities of BLE0, revealing the detailed structure and molecular mechanisms underlying its immunostimulatory activities [12-16].

The development of medicines and health-functional foods using natural products is actively advancing and, accordingly, the scientific basis for the safety of each natural product is considered important [17]. Although most extracts derived from natural products are safe, some have known toxicities [18-20]. Thus, when using natural products as medicines, or as ingredients in functional foods, safety evaluation is essential.

Therefore, in this study, the in vivo acute toxicity and in vitro genotoxicity of BLE0 were evaluated to establish preliminary safety data to enable the development of health-functional foods derived from BLE0.

\section{Materials and Methods}

\subsection{Preparation of $B L E 0$}

Pilot-scale manufactured BLE0 was obtained from young barley leaves according to a previously reported method with minor modifications [16]. Samples of young barley leaves, cultivated in Naju (Jeollanam-do, Korea) in 2017, were harvested 2 weeks after seeding. The polysaccharides (BLE0) from barley leaves were prepared by enzyme-assisted extraction using commercial pectinase Plantase MAX ${ }^{\circledR}$ from Aspergillus niger (Vision, Seongnam, Korea). The dried barley leaves (10 kg) were minced and suspended in $300 \mathrm{~L}$ of distilled water (solid/liquid ratio, $1: 30 \mathrm{w} / \mathrm{v}$ ). The $\mathrm{pH}$ of the suspension was adjusted to an optimal $\mathrm{pH}$ range of 4.5-5.0. Enzyme digestion and extraction were conducted at $50{ }^{\circ} \mathrm{C}$ for 3 days in a circulation extraction tank in which $1.5 \%$ of pectinase $(v / w)$ was added twice. After the enzymatic hydrolysis process, the extract from the enzyme hydrolyzate was filtered through a $0.5 \mu \mathrm{m}$ depth cartridge filter (Pall Corporation, Port Washington, NY, USA), and concentrated to the final soluble solids content of $5.0^{\circ}$ Brix at reduced pressure. After the gradual addition of 2.5 times $95 \%(v / v)$ cold ethanol to the aqueous extract, the extract was stored overnight at $-20{ }^{\circ} \mathrm{C}$ to precipitate crude polysaccharides. The precipitate was collected by centrifugation, dissolved in water (solid/liquid ratio, $1: 7 \mathrm{w} / \mathrm{v}$ ) at $50^{\circ} \mathrm{C}$ and then dried using a pilot-scale spray dryer (SD Pilot 2010; Ein system, Seoul, Korea) to yield BLE0. Spray drying was performed with an inlet air temperature of $190^{\circ} \mathrm{C}$ and an outlet air temperature of $90^{\circ} \mathrm{C}$ while maintaining the temperature of the sample sludge at $50^{\circ} \mathrm{C}$. The spray dryer sample feed velocity was $10 \mathrm{~L} / \mathrm{h}$. No additives were used. To prevent cross-contamination between samples, the drying chamber was washed with detergent and hot water and a run without sample was performed between samples.

\subsection{Chemical Composition of BLEO}

The yield (\%) was determined as dry weight of the obtained polysaccharide sample relative to the weight of young barley leaves. Total sugar content was determined using the phenol-sulfuric acid method (standard: glucose) [21] and acidic sugar content was determined by the carbazole sulfuric acid method (standard: D-galacturonic acid) [22]. Protein content was determined by the Bradford method (standard: bovine serum albumin) [23] and 2-Keto-3-Deoxy-D-mannooctanoic acid (KDO)-like materials were measured by a modified thiobarbituric acid-positive method (standard: KDO) [24]. The monosaccharide composition of BLE0 was analyzed using high-performance anion-exchange chromatography with pulsed amperometric detection (HPAEC-PAD) in an ICS-5000 chromatography system (Dionex, Sunnyvale, CA, USA) after polysaccharides were degraded into monosaccharides 
by acid hydrolysis with $2 \mathrm{M}$ trifluoroacetic acid in a boiling water bath for $4 \mathrm{~h}$. The hydrolysate was adjusted to $\mathrm{pH}$ 6.0, diluted with ultrapure water and then filtrated through $0.22 \mu \mathrm{m}$ hydrophilic membranes. Table 1 shows the experimental conditions for HPAEC-PAD analysis. Neutral sugars were eluted with $18 \mathrm{mM} \mathrm{NaOH}$, and uronic acids were eluted with $100 \mathrm{mM} \mathrm{NaOAc}$ in $100 \mathrm{mM} \mathrm{NaOH}$ (isocratic elution).

Table 1. High-performance anion-exchange chromatography with pulsed amperometric detection (HPAEC-PAD) operating condition for sugar composition analysis.

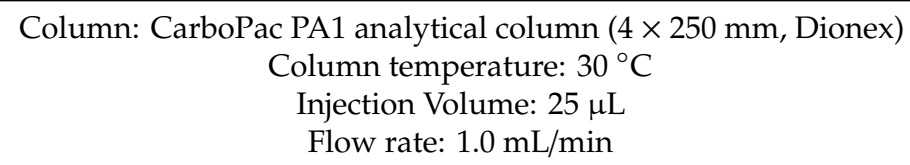

\subsection{Bacterial Reverse Mutation Test}

To confirm the mutagenicity of BLE0, a bacterial reverse mutation assay was performed based on the Organization for Economic Cooperation and Development (OECD) Test Guideline 471 (TG471) [25] and the guidelines of the National Institute of Food and Drug Safety Evaluation (NIFDS) of Korea (No. 2014-136) [26]. Histidine-requiring strains (Salmonella typhimurium TA98, TA100, TA1535, and TA1537) and a tryptophan-requiring strain (Escherichia coli WP2uvrA) were used. As a metabolic activation system, S9 mix (Moltox., Boone, NC, USA: $50 \mu \mathrm{L}$ of rat liver S9 fraction in $1 \mathrm{~mL}$ of S9 mix, $5 \mu \mathrm{M}$ glucose-6-phosphate, $8 \mu \mathrm{M} \mathrm{MgCl}_{2} \cdot 6 \mathrm{H}_{2} \mathrm{O}, 33 \mu \mathrm{M} \mathrm{KCl}, 4 \mu \mathrm{M} \mathrm{NADPH}, 4 \mu \mathrm{M} \mathrm{NADH}, 100 \mu \mathrm{M}$ sodium phosphate buffer, $\mathrm{pH}$ 7.4) was used. For all strains, colony counts were measured with and without the metabolic activation system. Sodium azide (SA), 2-Nitrofluorene (2-NF), acridine mutagen ICR 191 (ICR-191), 4-Nitroquinoline-1-oxide (4NQO), 2-Aminoanthracene (2-AA), and benzo[a]pyrene (B[a]P) were used as positive controls. All positive controls were obtained from Sigma-Aldrich (St. Louis, MO, USA).

\subsection{In Vitro Mammalian Chromosomal Aberration Assay}

A BLE0-induced chromosomal aberration test was performed based on OECD guideline TG473 [27] and guidelines of NIFDS of Korea (No. 2014-136) [26] using Chinese hamster lung fibroblast (CHL/IU) cells. CHL/IU cells (CRL-1935) were procured from the American Type Culture Collection (Manassas, VA, USA). Cells were maintained in minimum essential medium (Gibco BRL, Grand Island, NY, USA) containing $10 \%$ fetal bovine serum. Cells were cultured by adding test or control substances in the absence and presence of an S9 metabolic activation system (S9 mix: $200 \mu \mathrm{L}$ of rat liver S9 fraction in $1 \mathrm{~mL}$ of $\mathrm{S} 9 \mathrm{mix}, 5 \mu \mathrm{M}$ glucose-6-phosphate, $8 \mu \mathrm{M} \mathrm{MgCl}_{2} \cdot 6 \mathrm{H}_{2} \mathrm{O}, 33 \mu \mathrm{M} \mathrm{KCl}, 5 \mu \mathrm{M}$ NADP). A solution of colchicine (final concentration $1 \mu \mathrm{M}$ ) was added approximately $2 \mathrm{~h}$ before the end of the culture. After incubation, the culture medium containing metaphase cells was centrifuged at $200 \mathrm{~g}$ for $5 \mathrm{~min}$ followed by the addition of a fixing solution (glacial acetic acid: methanol $=1: 3 v / v$ ). The cell suspension was placed on a glass slide to prepare a slide sample. After drying, the samples were stained for $20 \mathrm{~min}$ with a Giemsa staining solution (5\%) and analyzed for chromosomal abnormalities under a 1000-fold microscope.

\subsection{Acute Oral Toxicity Test}

For acute oral toxicity, 6-week-old specific-pathogen-free female and male Sprague-Dawley (SD) rats were procured from Daehan Biolink (Eumseong, Korea). An irradiation-sterilized pellet diet for lab animals (LabDiet 5L79; Charles River, Wilmington, MA, USA) and groundwater (UV sterilized and filtered) were provided ad libitum. All animal experiments were approved by the Institutional Animal Care and Use Committee of Croen Inc. (19R073; Suwon, Korea).

A single-dose acute oral toxicity assay was performed based on the guidelines (No. 2017-71) of the NIFDS of Korea [28]. SD rats were selected as they are extensively used in general toxicity studies, 
presenting abundant comparable evidence [29]. The experimental animals included 22 males and 22 females, weighing 149.4-171.0 g and 137.0-153.3 g, respectively. After animal acquisition, a 7-day acclimatization period was allowed. Body weight was measured from the day before the start of BLE0 administration, recorded as 233.3-263.4 $\mathrm{g}$ in males and 168.6-195.7 $\mathrm{g}$ in females (supplementary material Table S1). The rats were randomly divided to a control group and three test groups (1250, 2500 , and $5000 \mathrm{mg} / \mathrm{kg}$ ). A total of 40 animals were used (5/sex/group). In the dose-range finding study $(n=4)$, no dead animals were observed at $5000 \mathrm{mg} / \mathrm{kg}$. Hence, $5000 \mathrm{mg} / \mathrm{kg}$ was set as the high-dose group, $2500 \mathrm{mg} / \mathrm{kg}$ as the medium-dose group and $1250 \mathrm{mg} / \mathrm{kg}$ as the low-dose group. The negative control group was administered sterile distilled water (Lot No.: V3T7B21: Daihan Pharmaceutical, Seoul, Korea) as a vehicle control. After an overnight fast, BLE0 was administered as a single oral dose using a feeding needle $(20 \mathrm{~mL} / \mathrm{kg})$, and food was provided $3 \mathrm{~h}$ after administration. All experimental animals were observed for general clinical signs as well as weight measurements. On the day of administration, clinical signs were observed every hour until $4 \mathrm{~h}$ after administration, and once every 14 days thereafter. Additionally, body weights were measured 1, 3, 7, and 14 days after administration. On the 14th day after administration, all organs were visually examined following animal autopsies after $\mathrm{CO}_{2}$ euthanasia.

\subsection{Statistical Analysis}

Experimental data are expressed as mean \pm standard deviation. For animals, body weight data were statistically analyzed by one-way analysis of variance. For the in vitro chromosomal aberration test, Fisher's exact test was used to compare data between the negative control group and the treatment groups or the positive control group. The significance level was set at $p<0.05$. All statistical analyses were conducted using SPSS version 24 (SPSS Inc., Chicago, IL, USA).

\section{Results}

\subsection{Chemical Composition of BLEO}

Previously, we obtained a polysaccharide fraction (BLE0) from pectinase hydrolysate of young barley leaves with immunostimulatory and antiosteoporotic effects [12-16]. It was demonstrated that pectinase application was a useful method for obtaining polysaccharides with enhanced immune activity from barley leaves [12]. In this study, BLE0 was obtained from young barley leaves by utilizing pectinase-assisted extraction at a pilot-scale for commercial production. Extraction yield of BLE0 was $4.1 \%$. Neutral sugars $(79.2 \%)$ and uronic acid $(18.0 \%)$ comprised the main parts of BLE0, demonstrating a high carbohydrate content ( $>97 \%$ ) summed by neutral and acidic sugars (Table 2). Additionally, BLE0 contained protein and KDO-like materials. The sugar composition of BLE0 was further analyzed by HPAEC-PAD revealing that BLE0 was mainly composed of xylose, galactose, arabinose, glucose and galacturonic acid, in addition to fucose, rhamnose and glucuronic acid (Supplementary Material Figure S1). In terms of peak area, the high levels of arabinose, xylose, galactose and galacturonic acid indicated that BLE0 possessed arabinoxylan and rhamnogalacturonan I-rich structures, which is in accordance with previous results [14]. Additionally, the chemical and monosaccharide compositions of BLE0 were similar to those in previous results of BLE0 prepared by a laboratory-scale experiment [16], indicating stable BLE0 production from the pilot-scale process.

Table 2. Chemical properties of polysaccharides manufactured from pectinase-treated $H$. vulgare leaves (BLE0).

\begin{tabular}{cc}
\hline & BLE0 $^{{ }^{1}}$ \\
\hline Yield (\%) & $4.1 \pm 0.3^{2}$ \\
\hline Chemical composition $(\%)^{3}$ & \\
\hline Neutral sugar & $79.2 \pm 0.1$ \\
\hline
\end{tabular}


Table 2. Cont.

\begin{tabular}{cc}
\hline Uronic acid & $18.0 \pm 1.4$ \\
\hline 2-Keto-3-Deoxy-Mannoctanoic acid (KDO)-like materials & $2.3 \pm 1.2$ \\
\hline Protein & $0.4 \pm 0.0$ \\
\hline Composition of sugar $(\mathrm{mol} \%)^{4}$ & \\
\hline Arabinose & $16.9 \pm 0.0$ \\
\hline Fucose & $0.8 \pm 0.0$ \\
\hline Galactose & $18.5 \pm 0.1$ \\
\hline Glucose & $14.8 \pm 0.1$ \\
\hline Mannose & nd ${ }^{5}$ \\
\hline Rhamnose & $5.5 \pm 0.1$ \\
\hline Xylose & $29.4 \pm 0.2$ \\
\hline Galacturonic acid & $11.5 \pm 0.2$ \\
\hline Glucuronic acid & $2.6 \pm 0.0$
\end{tabular}

${ }^{1}$ BLE0 was manufactured on a pilot-scale for industrial applications; ${ }^{2}$ values represent the means and standard deviations on BLE0 prepared by three independent experiments; ${ }^{3}$ percentage $(\%)$ of each dry material; ${ }^{4} \mathrm{Mol} \%$ was calculated from detected total sugar; ${ }^{5}$ nd, not detected.

\subsection{Bacterial Reverse Mutation Test}

The bacterial reverse mutation assay was conducted using histidine demand test strains (S. typhimurium) [30] and a tryptophan demand test strain (E. coli) [31]. In all tested strains, no cytotoxicity was detected at BLE0 concentrations up to $5000 \mu \mathrm{g} /$ plate. As shown in Figure 1, the mean number of colonies in the BLE0-treated groups did not show any increases, regardless of treatment with the S9 metabolic activation system in all tested strains. On the other hand, the mean revertant of the positive control for each test strain exhibited a clear increase. These results suggested that the experimental system worked well. Therefore, it was confirmed that BLE0 does not induce a reverse mutation in the evaluated bacterial strains used as a standard test method.
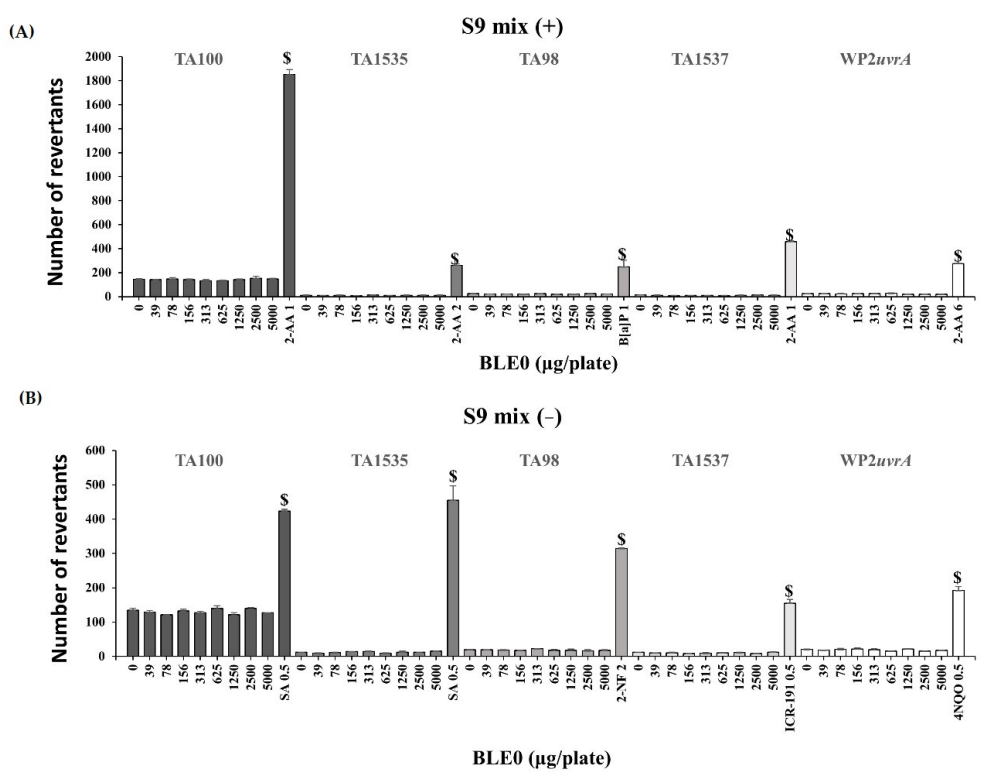

Figure 1. Effect of BLE0 on bacterial reverse mutation (A) with (+S9 mix) or (B) without (-S9 mix) the metabolic activation of Salmonella typhimurium (TA100, TA1535, TA98, and TA1537) and Escherichia coli (WP2uvrA). \$, positive bacterial reverse mutation induced by positive control; SA, sodium azide; 2-AA, 2-Aminoanthracene; 2-NF, 2-nitrofluorene; ICR-191, acridine mutagen ICR 191; 4NQO, 4-Nitroquinoline-1-oxide; B[a]P, benzo[a]pyrene. 


\subsection{In Vitro Mammalian Chromosomal Aberration Assay}

BLE0-induced chromosomal abnormalities were investigated using CHL/IU cells. BLE0 treatment was performed for 6 or $24 \mathrm{~h}$ and structural and numerical aberrations were observed after Giemsa staining. Structural aberrations analyzed the gap, break, exchange and the fragment of chromosome and chromatid; numerical aberrations evaluated the frequency of endoreduplication (ER) and polyploidy (PP). The frequency of structural abnormalities in the BLE0-treated and negative control cells was found to be $0 \%$, indicating that the frequency of structural abnormalities was not increased by BLE0 administration. In contrast, in the positive control groups, structural abnormality of chromosomes increased significantly. Additionally, the frequency of numerical abnormalities induced by BLE0 did not demonstrate a significant difference from the negative control group. These results suggested that BLE0 does not cause chromosomal abnormalities (Table 3).

$$
\operatorname{RICC}(\%)=\frac{\text { Cell number increase in treated cultures }(\text { final }- \text { initial })}{\text { Cell number increase in negative control cultures }(\text { final }- \text { initial })} \times 100 \text {. }
$$

Table 3. In vitro chromosomal aberration assay in Chinese hamster lung cells treated with BLE0.

\begin{tabular}{|c|c|c|c|c|c|}
\hline $\begin{array}{l}\text { Trt-Rec Time }{ }^{1} \\
\text { (h) }\end{array}$ & S9 mix $^{2}$ & $\begin{array}{c}\text { Dose } \\
(\mu \mathrm{g} / \mathrm{mL})\end{array}$ & $\begin{array}{c}\text { No. Aberrant Metaphase } \\
(\%)\end{array}$ & $\begin{array}{c}\mathrm{PP}+\mathrm{ER}^{3,4} \\
(\%)\end{array}$ & $\begin{array}{c}\text { RICC }^{5} \\
(\%)\end{array}$ \\
\hline \multirow{8}{*}{$6-18$} & \multirow{8}{*}{+} & 0 & $0(0.00)$ & $0(0.00)$ & 100 \\
\hline & & 31.25 & $0(0.00)$ & $0(0.00)$ & 96 \\
\hline & & 62.5 & $0(0.00)$ & $0(0.00)$ & 98 \\
\hline & & 125 & $0(0.00)$ & $0(0.00)$ & 89 \\
\hline & & 250 & $0(0.00)$ & $0(0.00)$ & 89 \\
\hline & & 500 & $0(0.00)$ & $0(0.00)$ & 93 \\
\hline & & 1000 & $0(0.00)$ & $0(0.00)$ & 83 \\
\hline & & $\mathrm{B}[\mathrm{a}] \mathrm{P} 20$ & $51(34.00) * *$ & $0(0.00)$ & 52 \\
\hline \multirow{8}{*}{$6-18$} & \multirow{8}{*}{-} & 0 & $0(0.00)$ & $0(0.00)$ & 100 \\
\hline & & 31.25 & $0(0.00)$ & $0(0.00)$ & 88 \\
\hline & & 62.5 & $0(0.00)$ & $0(0.00)$ & 87 \\
\hline & & 125 & $0(0.00)$ & $0(0.00)$ & 91 \\
\hline & & 250 & $0(0.00)$ & $0(0.00)$ & 90 \\
\hline & & 500 & $0(0.00)$ & $0(0.00)$ & 89 \\
\hline & & 1000 & $0(0.00)$ & $0(0.00)$ & 77 \\
\hline & & 4NQO 0.4 & $18(12.00)^{* *}$ & $0(0.00)$ & 78 \\
\hline \multirow{8}{*}{$24-0$} & \multirow{8}{*}{-} & 0 & $0(0.00)$ & $0(0.00)$ & 100 \\
\hline & & 31.25 & $0(0.00)$ & $0(0.00)$ & 102 \\
\hline & & 62.5 & $0(0.00)$ & $0(0.00)$ & 98 \\
\hline & & 125 & $0(0.00)$ & $0(0.00)$ & 99 \\
\hline & & 250 & $0(0.00)$ & $0(0.00)$ & 92 \\
\hline & & 500 & $0(0.00)$ & $0(0.00)$ & 74 \\
\hline & & 1000 & $0(0.00)$ & $0(0.00)$ & 68 \\
\hline & & 4NQO 0.4 & $20(13.33) * *$ & $0(0.00)$ & 87 \\
\hline
\end{tabular}

${ }^{1} \mathrm{Trt}-\mathrm{Rec}$ Time, treatment time, recovery time; ${ }^{2}$ the absence (-) or presence (+) of S9 mix; ${ }^{3}$ number of cells in metaphase with chromosomal aberrations; after gaps were excluded, 150 metaphase cells/culture were examined; ${ }^{4} \mathrm{PP}$, polyploidy; ER, endoreduplication; ${ }^{5} \mathrm{RICC}$, relative increase in cell count (Equation (1)); ${ }^{* *} p<0.01$ compared to the negative control (Dose $=0 \mu \mathrm{g} / \mathrm{mL}$; Fisher's exact test).

\subsection{Acute Oral Toxicity Test}

To determine single-dose toxicity and the approximate lethal dose of BLE0, the test substance was orally administered once to male and female SD rats and general symptoms, weight change and deaths were observed for 14 days after administration. No animals died during the experimental period and no experimental animal demonstrated unusual general clinical features. Body weight was measured 
before and 1, 4, 7 and 14 days after BLE0 administration. Only normal weight gain was observed with no significant changes measured between the BLE0 treated groups and the control group (Figure 2 and Supplementary Material Table S1). On the 14th experimental day, autopsies were performed on the organs of all surviving animals with no specific findings observed in all experimental animals (data not shown). The median lethal dose $\left(\mathrm{LD}_{50}\right)$ of BLE0 was $>5000 \mathrm{mg} / \mathrm{kg}$.
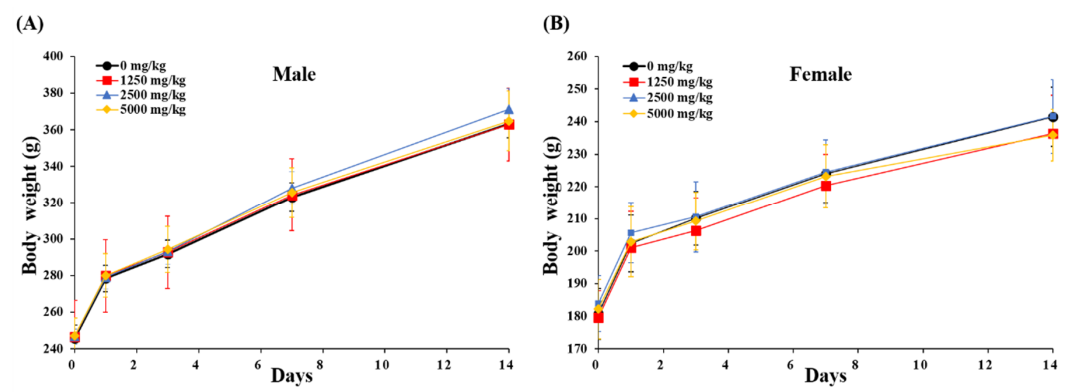

Figure 2. Body weight change of male (A) and female (B) rats in the single-dose oral toxicity test of BLE0. The day of administration was designated as day 0 . Male and female rats were randomly divided into four groups ( $n=5 / \operatorname{sex} /$ group). Data are presented as mean \pm standard deviation.

\section{Discussion}

In 2017, the market for food and medicine derived from natural products was approximately 1 trillion dollars worldwide, growing by $8-10 \%$ every year [32]. Notably, natural health-functional foods and medicines have demonstrated relatively low toxicity, with shorter development times when compared to synthetic substances [33]. Additionally, unlike synthetic materials, diverse active ingredients were found to be present in one natural product, thereby enhancing clinical effects during disease conditions [34]. Hence, research on natural products is being actively conducted in several countries. However, systematic safety evaluation of natural products used as raw materials for pharmaceuticals and functional foods is still insufficient when compared to studies evaluating efficacy. In Korea, a list of approved compounds/foods is presented under relevant regulations. However, safety evaluations are essential when new compounds/foods are introduced into the market [26]. In our preliminary studies, we elucidated the major components and structural characteristics of BLE0 [12,13]. Moreover, our previous studies showed that BLE0 possesses immune-enhancing and anti-osteoporitic activities [14-16]. However, safety assessment data are crucial to exclude the potential toxicities of BLE0.

Therefore, in this study, we aimed to establish preliminary safety data that would permit the development of BLE0 as a health-functional food. Accordingly, in vivo acute oral toxicity and in vitro genotoxicity tests were performed to assess the safety of BLE0.

The bacterial reverse mutation assay is a widely used method for assessing whether a test substance can induce mutations in the DNA of model microorganisms [30]. The bacterial reverse mutation test was performed to determine whether BLE0 could induce a return mutation in the S. typhimurium histidine-requiring strains (TA98, TA100, TA1535, TA1537) and the E. coli tryptophan-requiring strain (WP2uvrA), in the absence and presence of a metabolic activation system. As a metabolic activation system, a cofactor was added to the liver homogenate of rats induced with Aroclor-1254. Regardless of the absence or presence of the metabolic activation system, the average number of colonies (S. typhimurium TA98, TA100, TA1535, TA1537, and E. coli WP2uvrA) in the BLE0 treatment groups did not increase. Conversely, a positive increase in the colony count was observed in all positive control groups, suggesting that BLE0 does not cause a return mutation in the test strains used under these test conditions.

Studies regarding chromosomal DNA damage induced by test substances are essential for genotoxicity screening [35]. In this study, a chromosomal aberration test was performed to examine the clastogenicity of BLE0. Chromosomal abnormalities were identified and numbered based on the atlas 
of chromosome aberrations by chemicals [36]. In the BLE0 treatment groups, the frequency of abnormal metaphase expression was confirmed as $0 \%$, with or without the metabolic activation system, and the absence of chromosomal abnormalities was verified. In contrast, in all positive controls, the frequency of abnormal mid-phase expression was significantly increased. Based on the above results it was concluded that BLE0 did not cause chromosomal abnormalities in the CHL/IU cells under the current experimental conditions. Taken together, the present genotoxicity data for BLE0 were consistent with previous reports that demonstrated no mutagenicity of the polysaccharide fraction from various plant extracts [37-39].

A single-dose oral administration of BLE0 did not result in abnormal changes in body weight, clinical signs, mortality or autopsy findings in SD rats. Therefore, under this acute oral toxicity experiment condition, the median lethal dose $\left(\mathrm{LD}_{50}\right)$ of $\mathrm{BLE} 0$ was determined to be higher than $5000 \mathrm{mg} / \mathrm{kg}$. Based on OECD test guidelines, BLE0 was considered nontoxic owing to the absence of deaths at a dose of $2000 \mathrm{mg} / \mathrm{kg}$ [29], thus suggesting the non-toxicity of BLE0. Previously, the polysaccharide fraction of plant extracts demonstrated no toxicity after a single-dose oral administration of $5000 \mathrm{mg} / \mathrm{kg}$ in SD rats [37,40]. The present results are in accordance with previous results.

In this study, under the given experimental conditions, BLE0 did not demonstrate in vitro genotoxicity or in vivo acute oral toxicity. However, in addition to the preliminary safety data obtained in this study, in vivo micronucleus and subchronic ( 28 days) oral toxicity experiments should be conducted to satisfy the overall safety requirements for the development of health-functional foods.

\section{Conclusions}

In the present study, an in vitro genetic toxicity test and a single-dose acute oral toxicity test were performed to evaluate the feasibility of using BLE0 (a bioactive polysaccharide fraction isolated from young barley leaves) as a functional food material. For genotoxicity testing, bacterial reverse mutation and in vitro chromosome aberration tests were used. In the bacterial reverse mutation assay, no significant increase in colony number was observed after BLE0 treatment in the absence or presence of an S9 metabolic activation system. Additionally, in the in vitro chromosome aberration test, no chromosomal abnormalities were induced in the BLE0 treated groups. In a single-dose acute oral toxicity test, oral administration of BLE0 $(0,1250,2500$, and $5000 \mathrm{mg} / \mathrm{kg}$ ) presented no abnormal symptoms, including death or serious weight changes, in SD rats. Therefore, it was concluded that the $\mathrm{LD}_{50}$ of BLE0 was greater than $5000 \mathrm{mg} / \mathrm{kg}$. Collectively, these results suggest that BLE0 does not cause genetic toxicity by inducing bacterial reverse mutations or chromosomal abnormalities and presents no acute oral toxicity in SD rats.

Supplementary Materials: The following are available online at http://www.mdpi.com/2304-8158/9/6/809/s1, Figure S1: HPAEC-PAD chromatograms showing the monosaccharide compositions of BLE0, Table S1: Body weight.

Author Contributions: Conceptualization, C.-W.C., K.-T.L., and H.-D.H.; methodology, C.-W.C., Y.-R.S., W.-C.L., Y.K.R., and J.W.C.; data curation, Y.-H.H.; writing-original draft preparation, C.-W.C. and Y.-R.S.; writing-review and editing, Y.-H.H., K.-T.L., and H.-D.H.; supervision, H.-D.H.; project administration, C.-W.C. and H.-D.H.; funding acquisition, H.-D.H. All authors have read and agreed to the published version of the manuscript.

Funding: This research was funded by Ministry of Science and ICT, Korea, Grant number: Korea Food Research Institute E0201100.

Conflicts of Interest: The authors declare no conflict of interest.

\section{References}

1. Yamaura, K.; Nakayama, N.; Shimada, M.; Bi, Y.; Fukata, H.; Ueno, K. Antidepressant-like effects of young green barley leaf (Hordeum vulgare L.) in the mouse forced swimming test. Pharmacogn. Res. 2012, 4, 22-26. [CrossRef] [PubMed]

2. Ferreres, F.; Krskova, Z.; Goncalves, R.F.; Valentao, P.; Pereira, J.A.; Dusek, J.; Martin, J.; Andrade, P.B. Free water-soluble phenolics profiling in barley (Hordeum vulgare L.). J. Agric. Food Chem. 2009, 57, 2405-2409. [CrossRef] [PubMed] 
3. Markham, K.R.; Mitchell, K.A. The mis-identification of the major antioxidant flavonoids in young barley (Hordeum vulgare) leaves. Z. Naturforschung C J. Biosci. 2003, 58, 53-56. [CrossRef]

4. Park, S.E.; Seo, S.H.; Kim, E.J.; Lee, K.M.; Son, H.S. Quality characteristics of string cheese prepared with barley sprouts. J. Korean Soc. Food Sci. Nutr. 2017, 48, 841-847.

5. Simeonova, R.; Vitcheva, V.; Kondeva-Burdina, M.; Krasteva, I.; Manov, V.; Mitcheva, M. Hepatoprotective and antioxidant effects of saponarin, isolated from Gypsophila trichotoma Wend. on paracetamol-induced liver damage in rats. Biomed. Res. Int. 2013, 2013, 757126. [CrossRef]

6. Sengupta, S.; Mukherjee, A.; Goswami, R.; Basu, S. Hypoglycemic activity of the antioxidant saponarin, characterized as alpha-glucosidase inhibitor present in Tinospora cordifolia. J. Enzym. Inhib. Med. Chem. 2009, 24, 684-690. [CrossRef]

7. Seo, W.D.; Yuk, H.J.; Curtis-Long, M.J.; Jang, K.C.; Lee, J.H.; Han, S.I.; Kang, H.W.; Nam, M.H.; Lee, S.J.; Lee, J.H.; et al. Effect of the growth stage and cultivar on policosanol profiles of barley sprouts and their adenosine 5'-monophosphate-activated protein kinase activation. J. Agric. Food. Chem. 2013, 61, 1117-1123. [CrossRef]

8. Benedet, J.A.; Umeda, H.; Shibamoto, T. Antioxidant activity of flavonoids isolated from young green barley leaves toward biological lipid samples. J. Agric. Food Chem. 2007, 55, 5499-5504. [CrossRef]

9. Takano, A.; Kamiya, T.; Tomozawa, H.; Ueno, S.; Tsubata, M.; Ikeguchi, M.; Takagaki, K.; Okushima, A.; Miyata, Y.; Tamaru, S.; et al. Insoluble fiber in young barley leaf suppresses the increment of postprandial blood glucose level by increasing the digesta viscosity. Evid. Based Complement. Altern. Med. 2013, 2013, 137871. [CrossRef]

10. Yu, Y.; Shen, M.; Song, Q.; Xie, J. Biological activities and pharmaceutical applications of polysaccharide from natural resources: A review. Carbohydr. Polym. 2018, 183, 91-101. [CrossRef]

11. Liu, J.; Willfor, S.; Xu, C. A review of bioactive plant polysaccharides: Biological activities, functionalization, and biomedical applications. Bioact. Carbohydr. Diet. Fibre 2015, 5, 31-61. [CrossRef]

12. Kim, H.; Kwak, B.S.; Hong, H.D.; Suh, H.J.; Shin, K.S. Structural features of immunostimulatory polysaccharide purified from pectinase hydrolysate of barley leaf. Int. J. Biol. Macromol. 2016, 87, 308-316. [CrossRef] [PubMed]

13. Kim, H.; Hong, H.D.; Shin, K.S. Structure elucidation of an immunostimulatory arabinoxylan-type polysaccharide prepared from young barley leaves (Hordeum vulgare L.). Carbohydr. Polym. 2017, 157, $282-293$. [CrossRef]

14. Kim, H.; Yu, K.W.; Hong, H.D.; Shin, K.S. Effect of arabinoxylan-and rhamnogalacturonan I-rich polysaccharides isolated from young barley leaf on intestinal immunostimulatory activity. J. Funct. Foods 2017, 35, 384-390. [CrossRef]

15. Hwang, Y.H.; Ha, H.; Kim, R.; Cho, C.W.; Song, Y.R.; Hong, H.D.; Kim, T. Protective effects of a polysaccharide BLE0 isolated from barley leaf on bone loss in ovariectomized mice. Int. J. Biol. Macromol. 2019, 123, 314-321. [CrossRef]

16. Han, H.S.; Shin, J.S.; Song, Y.R.; Rhee, Y.K.; Cho, C.W.; Ryu, J.H.; Inn, K.S.; Hong, H.D.; Lee, K.T. Immunostimulatory effects of polysaccharides isolated from young barley leaves (Hordeum vulgare L.) with dual activation of Th1 and Th2 in splenic T cells and cyclophosphamide-induced immunosuppressed mice. Int. J. Biol. Macromol. 2020, 147, 954-964. [CrossRef]

17. Vettorazzi, A.; Lopez de Cerain, A.; Sanz-Serrano, J.; Gil, A.G.; Azqueta, A. European Regulatory Framework and Safety Assessment of Food-Related Bioactive Compounds. Nutrients 2020, 12, 613. [CrossRef]

18. Chan, K. Some aspects of toxic contaminants in herbal medicines. Chemosphere 2003, 52, 1361-1371. [CrossRef]

19. Hwang, Y.H.; Kim, T.; Cho, W.K.; Yang, H.J.; Kwak, D.H.; Ha, H.; Song, K.H.; Ma, J.Y. In vitro and in vivo genotoxicity assessment of Aristolochia manshuriensis Kom. Evid. Based Complement. Altern. Med. 2012, 2012, 412736. [CrossRef]

20. Hwang, Y.H.; Park, H.; Ma, J.Y. In vitro and in vivo safety evaluation of Acer tegmentosum. J. Ethnopharmacol. 2013, 148, 99-105. [CrossRef]

21. Dubois, M.; Gilles, K.; Hamilton, J.K.; Rebers, P.A.; Smith, F. A colorimetric method for the determination of sugars. Nature 1951, 168, 167. [CrossRef]

22. Blumenkrantz, N.; Asboe-Hansen, G. New method for quantitative determination of uronic acids. Anal. Biochem. 1973, 54, 484-489. [CrossRef] 
23. Bradford, M.M. A rapid and sensitive method for the quantitation of microgram quantities of protein utilizing the principle of protein-dye binding. Anal. Biochem. 1976, 72, 248-254. [CrossRef]

24. Karkhanis, Y.D.; Zeltner, J.Y.; Jackson, J.J.; Carlo, D.J. A new and improved microassay to determine 2-keto-3-deoxyoctonate in lipopolysaccharide of Gram-negative bacteria. Anal. Biochem. 1978, 85, 595-601. [CrossRef]

25. OECD. Test No. 471: Bacterial Reverse Mutation Test. In OECD Guidelines for the Testing of Chemicals; Section 4; OECD Publishing: Paris, France, 1997.

26. National Institute of Food and Drug Safety Evaluation, Korea. Ministry of Food and Drug Safety Notification No. 2016-141 'Regulation on Approval of Functional Ingredient for Health Functional Food'; Guidebook on Ministry of Food and Drug Safety Reference Standards: Seoul, Korea, 2016.

27. OECD. Test No. 473: In vitro Mammalian Chromosomal Aberration Test. In OECD Guidelines for the Testing of Chemicals; Section 4; OECD Publishing: Paris, France, 2016.

28. National Institute of Food and Drug Safety Evaluation, Korea. Ministry of Food and Drug Safety Notification No. 2017-71 'The standards of Toxicity Study for Medicinal Products'; Guidebook on Ministry of Food and Drug Safety Reference Standards: Seoul, Korea, 2017.

29. OECD. Test No. 420: Acute Oral Toxicity-Fixed Dose Procedure. In OECD Guidelines for the Testing of Chemicals; Section 4; OECD Publishing: Paris, France, 2002.

30. Maron, D.M.; Ames, B.N. Revised methods for the Salmonella mutagenicity test. Mutat. Res. 1983, 113, 173-215. [CrossRef]

31. Green, M.H.; Muriel, W.J. Mutagen testing using TRP+ reversion in Escherichia coli. Mutat. Res. 1976, 38, 3-32. [CrossRef]

32. Ahn, K. The worldwide trend of using botanical drugs and strategies for developing global drugs. BMB Rep. 2017, 50, 111-116. [CrossRef]

33. Markman, M. Safety issues in using complementary and alternative medicine. J. Clin. Oncol. 2002, 20, 39s-41s. [CrossRef]

34. Lahlou, M. Screening of natural products for drug discovery. Expert Opin. Drug Discov. 2007, 2, 697-705. [CrossRef]

35. European Medicines Agency. Guideline on the Assessment of Genotoxicity of Herbal Substances/Preparations; Committee on Herbal Medicinal Products (HPMC): London, UK, 2008.

36. JEMS-MMS. Atlas of Chromosome Aberration by Chemicals; Japanese Environmental Mutagen Society-Mammalian Mutagenicity Study Group: Tokyo, Japan, 1988.

37. Velusami, C.C.; Boddapati, S.R.; Hongasandra Srinivasa, S.; Richard, E.J.; Joseph, J.A.; Balasubramanian, M.; Agarwal, A. Safety evaluation of turmeric polysaccharide extract: Assessment of mutagenicity and acute oral toxicity. Biomed. Res. Int. 2013, 2013, 158348. [CrossRef]

38. Kim, K.I.; Kim, J.W.; Hong, B.S.; Shin, D.H.; Cho, H.Y.; Kim, H.K.; Yang, H.C. Antitumor, genotoxicity and anticlastogenic activities of polysaccharide from Curcuma zedoaria. Mol. Cells 2000, 10, 392-398.

39. Park, Y.C.; Kim, M.H.; Kim, J.W.; Kim, J.B.; Lee, J.G.; Yu, C.Y.; Kim, S.H.; Chung, I.M.; Kim, J.K.; Choi, R.N.; et al. Genotoxicity study of polysaccharide fraction from Astragalus membranaceus's aerial parts. Toxicol. Res. 2014, 30, 131-138. [CrossRef]

40. Chang, B.Y.; Cho, H.K.; Jun, K.Y.; Hur, J.M.; Park, H.; Kim, S.Y. Single oral toxicity study on the polysaccharide fraction of Pueraria lobata in rats. Korean J. Pharmacogn. 2010, 41, 210-215.

(C) 2020 by the authors. Licensee MDPI, Basel, Switzerland. This article is an open access article distributed under the terms and conditions of the Creative Commons Attribution (CC BY) license (http://creativecommons.org/licenses/by/4.0/). 